\title{
Simulated reductions in consumption of sugar-sweetened beverages improves diet quality in Lower Mississippi Delta adults
}

\author{
Jessica L. Thomson'**, Lisa M. Tussing-Humphreys', \\ Stephen J. Onufrak ${ }^{2}$, Carol L. Connell ${ }^{3}$, Jamie M. Zoellner ${ }^{4}$, \\ Margaret L. Bogle ${ }^{5}$ and Kathy Yadrick ${ }^{3}$
}

'Southern Regional Research Center, Agricultural Research Service, US Department of Agriculture, Baton Rouge, LA, USA; ${ }^{2}$ Mid South Area, Agricultural Research Service, US Department of Agriculture, Stoneville, MS, USA;

${ }^{3}$ Department of Nutrition and Food Systems, University of Southern Mississippi, Hattiesburg, MS, USA; ${ }^{4}$ Department of Human Nutrition, Foods and Exercise, Virginia Tech, Blacksburg, VA, USA; ${ }^{5}$ Delta Obesity Prevention Research Unit, Agricultural Research Service, US Department of Agriculture, Little Rock, AR, USA

Abstract

Background: Although the effects of replacing sugar-sweetened beverages (SSBs) with water on energy intake and body weight have been reported, little is known about how these replacements affect diet quality.

Objective: To simulate the effects of replacing SSBs with tap water on diet quality and total energy intake of Lower Mississippi Delta (LMD) adults.

Design: Retrospective analysis of cross-sectional dietary intake data using a representative sample of LMD adults $(n=1,689)$. Diet quality was measured using the Healthy Eating Index-2005 (HEI-2005) scores that were computed using the population ratio method. The effects of substituting SSBs with water on diet quality were simulated by replacing the targeted items' nutrient profile with tap water's profile.

Results: Simulating the replacement of SSBs with tap water at 25, 50, and 100\% levels resulted in 1-, 2.3-, and 3.8-point increases, respectively, in the HEI-2005 total score. Based on a mean daily intake of 2,011 kcal, $100 \%$ substitution of SSBs with tap water would result in $11 \%$ reduction in energy intake.

Conclusions: Replacing SSBs with water could substantially improve the diet quality of the LMD adult population and potentially lead to significant weight loss overtime. Prioritizing intervention efforts to focus on the replacement of SSBs with energy-free drinks may be the most efficacious approach for conveying potentially substantial health benefits in this and similar disadvantaged populations.

Keywords: added sugars; water; total energy intake; Southeastern United States

Received: 19 May 20II; Revised: 29 August 201 I; Accepted: 19 September 20I I; Published: 17 October 20II

$\mathrm{D}$ uring 1999-2004, two-thirds of adults in the United States (US) drank sugar-sweetened beverages (SSBs), averaging 28 ounces and $293 \mathrm{kcal}$ per day (1). The consumption of SSBs has been linked to many chronic diseases, including obesity, type 2 diabetes, hypertension, and heart disease (2-5). Consumption of such beverages is of particular concern in the US Lower Mississippi Delta (LMD) region because it suffers from disproportionate rates of obesity, type 2 diabetes, and other chronic conditions. The LMD encompasses counties and parishes within the three states of Arkansas,
Louisiana, and Mississippi. Based on the Chronic Disease Indicators for 2009, in these three states, adult obesity prevalence (as determined by self-reported heights and weights) ranged from 31.5 to $35.4 \%$ as compared to $26.9 \%$ for the United States overall (6). Prevalence of self-reported type 2 diabetes in adults ranged from 10.1 to $11.6 \%$ in the three states compared to a national prevalence of $8.3 \%$ (6). Additionally, diet quality in LMD adults is lower than that of US adults (7). Hence, dietary interventions that target decreasing SSB consumption could lower chronic disease risks in 
this region. In particular, reductions in prevalence rates of obesity and type 2 diabetes may occur as these two conditions are largely reversible through dietary modifications and weight loss.

While others have reported the effects of replacing SSBs with water on energy intake (8) and body weight (2) in adults, to date, no one has reported such effects on diet quality. Diet quality would be expected to improve with the replacement of SSBs with water. However, the magnitude of the resulting improvement in diet quality has not been reported. The effects of replacing SSBs with tap water on the diet quality of LMD adults were simulated using the Foods of Our Delta Study (FOODS) dataset and the Healthy Eating Index-2005 (HEI-2005), a measure of diet quality. The effects of SSB replacement with water on total energy intake were also explored. Because SSBs represent a top food source for total energy and carbohydrate intakes (9) as well as for discretionary calories in LMD adults, (10) they were singled out in the analyses.

\section{Methods}

\section{Participants}

Data from FOODS, a cross-sectional telephone survey of residents in the 36-county LMD region, conducted from January to June 2000 (11) were analyzed. A twostage stratified cluster sampling plan with list-assisted random-digit dialing was used in FOODS. Demographic information was collected during an initial interview. Dietary intake data were collected using the US Department of Agriculture 24-hour recall multiple pass methodology at an unscheduled follow-up telephone interview with the assistance of a foods measurement guide that had been mailed to survey participants. Dietary intake data were collected for 1,751 adults (participants 18 years of age or older) using a single 24-hour recall. A more detailed description of the FOODS methodology and the study population's mean dietary intakes may be found elsewhere (11). The procedures followed in FOODS were in accordance with ethical standards, and approval was obtained from the Institutional Review Board of Westat, Rockville, MD, USA. Implausible dietary records were excluded in the analyses based on the following criterion: intake $<500 \mathrm{kcal}$ or $>6,000 \mathrm{kcal}$ (12).

\section{Diet quality assessment}

The HEI-2005 is a measure of diet quality that assesses adherence to federal dietary guidance (13). The HEI-2005 has 12 components corresponding to total fruit (including 100\% fruit juice); whole fruit; total vegetables; dark green and orange vegetables and legumes; total grains; whole grains; milk; meat and beans; oils; saturated fat; sodium; and calories from solid fats, alcoholic beverages, and added sugars. The total score, calculated as the sum of the component scores, has a maximum value of 100 . Component scores are calculated using a density approach per 1,000 kcal or as a percentage of energy and range from 0 to 5 for fruit, vegetables, and grains components; 0-10 for milk, meat and beans, saturated fat, oils, and sodium components; and 0-20 for the solid fats, alcoholic beverages, and added sugars component. For each component, higher scores reflect better adherence to federal dietary guidance recommendations corresponding to that component. For fruit, vegetables, grains, meat and beans, and milk components, each score is based on MyPyramid equivalents consumed per 1,000 kcal. Oils and sodium component scores are calculated based on grams consumed per 1,000 kcal. Saturated fat and solid fats, alcoholic beverages, and added sugars component scores are calculated based on percentage of energy intake attributed to these energy sources. MyPyramid equivalents contributing to HEI-2005 index were derived using version 1.0 of the MyPyramid Equivalents Database that provides equivalents per $100 \mathrm{~g}$ for each unique eight-digit food code (14).

\section{Sugar-sweetened beverages}

Using eight-digit food codes (15), beverages were identified as sugar sweetened based on the categorization scheme of Wang et al. (16). For the LMD population, SSBs included: sweetened tea, carbonated soft drinks, fruit drinks, and non-carbonated beverages (e.g. fruitflavored drinks). Coffee, unsweetened tea, and unsweetened or sugar-free soft drinks were not included as SSBs in the analyses. To simulate the effects of substituting 25, 50 , and $100 \%$ of SSBs with tap water on HEI-2005 total and component scores, the SSBs' nutrient profiles were reduced by the respective amounts for the analyses. Only five nutrient variables (carbohydrates, energy, grams, saturated fat, and sodium) required modification because the FOODS dataset was linked to the MyPyramid Equivalents Database that only required these five variables to calculate MyPyramid equivalents. Nutrient data for tap water were inserted into the dataset because tap water contains a small amount of sodium, but no carbohydrates, energy, or saturated fat. Because, the gram weights for a serving (eight-fluid ounces) of tap water and the SSBs were not equivalent, the substituted amount of tap water (in grams) was adjusted using a ratio of tap water weight to SSB weight. This weighted amount was then used to calculate the amount of sodium to insert for the tap water substitutions.

It should be noted that some HEI-2005 component scores that would not have been expected to change (e.g. fruit, vegetables, grains, and saturated fat) did increase or decrease due to the reduction in total energy intake resulting from SSB replacement with water. Because component scores are based on the number of 
MyPyramid equivalents, calories, or grams consumed per $1,000 \mathrm{kcal}$, reducing the number of kcal results in increased densities. This increase in density can raise component scores for which a greater density is favorable (fruits, vegetables, grains, milk, meat and beans, and oils), but at the same time, lower component scores for which a greater density is unfavorable (saturated fat, sodium, solid fats, alcoholic beverages, and added sugars).

\section{Data analysis}

Statistical analyses were performed using the $\mathrm{SAS}^{\circledR}$ software (version 9.2, SAS Institute Inc., Cary, NC, 2008) and the SUDAAN ${ }^{\circledR}$ software (version 10.0.1, Research Triangle Institute, Research Triangle Park, NC, 2009). SAS survey and SUDAAN procedures were used to compute frequencies, means, and their associated confidence intervals. These procedures are tailored to account for the complex sampling design used in FOODS. Hence, the results are weighted and can be considered representative of the LMD adult population. The population ratio method was used to compute mean HEI-2005 scores and corresponding 95\% CI using jackknife variances for the overall population. This method computes scores using the ratio of the weighted sum of MyPyramid equivalent servings for the relevant HEI-2005 component to the weighted sum of energy intake for the entire population. It is the least biased way to estimate a mean HEI-2005 score for a population (17).

The potential impact of the SSB substitution with tap water on daily total energy intake was estimated at all three substitution levels. Changes in daily total energy intake were estimated by individually subtracting the population's mean total energy intake corresponding to 25,50 , and $100 \%$ substitution of SSBs with water from the population's actual mean total energy intake.

\section{Results}

Sixty-two of the 1,751 LMD adult respondents were excluded due to implausible dietary records, resulting in a total sample size of 1,689 adults. The sample was composed of $48 \%$ males, $43 \%$ African Americans, $21 \%$ less than 30 years of age, and $23 \%$ greater than 60 years of age (Table 1). Almost one-fourth of the population had a household income of less than $\$ 15,000$ per year and $23 \%$ of the population had less than a high school education (Table 1). Based on self-reported heights and weights, almost two-thirds of the population was either overweight $(25.0 \leq$ body mass index $\leq 29.90$ or obese $(30.0 \leq$ body mass index $\leq 39.9)$, and $4 \%$ was extremely obese (body mass index $\geq 40.0$ ) (Table 1 ). The mean daily energy intake for the LMD respondents was 2,011 kcal (Table 1).

The HEI-2005 total score for the population was 54.5 (Table 2). A $25 \%$ substitution of SSBs with tap water
Table 1. Demographic characteristics for Lower Mississippi Delta adults $(n=1,689)$

\begin{tabular}{|c|c|c|c|c|}
\hline \multirow[b]{2}{*}{ Characteristics } & \multirow[b]{2}{*}{$n$} & \multirow[b]{2}{*}{$\%$} & \multicolumn{2}{|c|}{$95 \% \mathrm{Cl}$} \\
\hline & & & Lower & Upper \\
\hline \multicolumn{5}{|l|}{ Sex } \\
\hline Male & 641 & 47.5 & 46.7 & 48.2 \\
\hline Female & 1048 & 52.5 & 51.8 & 53.3 \\
\hline \multicolumn{5}{|l|}{ Age (years) } \\
\hline $18-29$ & 306 & 20.7 & 18.4 & 23.1 \\
\hline $30-39$ & 321 & 19.1 & 17.3 & 20.8 \\
\hline $40-59$ & 605 & 36.9 & 34.6 & 39.2 \\
\hline$\geq 60$ & 456 & 23.3 & 21.5 & 25.1 \\
\hline Unknown & I & 0.0 & 0.0 & 0.1 \\
\hline \multicolumn{5}{|l|}{ Race } \\
\hline White & 827 & 53.8 & 53.1 & 54.4 \\
\hline African American & 812 & 42.8 & 41.7 & 43.9 \\
\hline Other & 34 & 2.5 & 1.5 & 3.5 \\
\hline Unknown & 16 & 0.9 & 0.5 & 1.4 \\
\hline \multicolumn{5}{|l|}{ Income } \\
\hline$<\$ 15,000$ & 465 & 23.1 & 20.9 & 25.4 \\
\hline$\$ 15,000-\$ 29,999$ & 417 & 24.8 & 22.3 & 27.3 \\
\hline$\geq \$ 30,000$ & 612 & 40.0 & 37.2 & 42.8 \\
\hline Unknown & 195 & 12.1 & 10.4 & 13.8 \\
\hline \multicolumn{5}{|l|}{ Education } \\
\hline$<$ High school & 407 & 23.2 & 20.9 & 25.5 \\
\hline High school & 568 & 36.8 & 34.5 & 39.1 \\
\hline$>$ High school & 691 & 38.5 & 36.1 & 40.9 \\
\hline Unknown & 23 & 1.5 & 0.7 & 2.2 \\
\hline \multicolumn{5}{|l|}{ Weight status } \\
\hline Healthy weight $(I 8.5 \leq \mathrm{BMI} \leq 24.9)$ & 536 & 31.3 & 28.8 & 33.9 \\
\hline Overweight $(25.0 \leq \mathrm{BMI} \leq 29.9)$ & 548 & 33.3 & 30.6 & 36.0 \\
\hline Obese $(30.0 \leq \mathrm{BMI} \leq 39.9)$ & 494 & 29.6 & 27.1 & 32.1 \\
\hline Extremely obese (BMI $\geq 40.0$ ) & 84 & 4.2 & 3.1 & 5.3 \\
\hline Unknown & 27 & 1.6 & 0.8 & 2.3 \\
\hline Total energy intake (kcal) & 1689 & 2011 & 1963 & 2059 \\
\hline
\end{tabular}

$\mathrm{Cl}$, confidence interval; $\mathrm{BMI}$, body mass index.

resulted in 1-point increases in both the HEI-2005 solid fats, alcoholic beverages, and added sugars component and total scores, whereas a $50 \%$ substitution resulted in 2.1- and 1.9-point increases in the solid fats, alcoholic beverages, and added sugars component and total scores, respectively (Table 2). A 100\% substitution resulted in a 4.4-point increase in the HEI-2005 solid fats, alcoholic beverages, and added sugars component score and a 3.8point increase in the total score (Table 2). All other component scores except saturated fat and sodium also improved with increasing SSB substitution amounts. Based on a mean daily intake of $2,011 \mathrm{kcal}, 25,50$, and $100 \%$ substitution of SSBs with tap water would result in 3,5 , and $11 \%$ reductions, respectively, in energy intake (Table 3). 


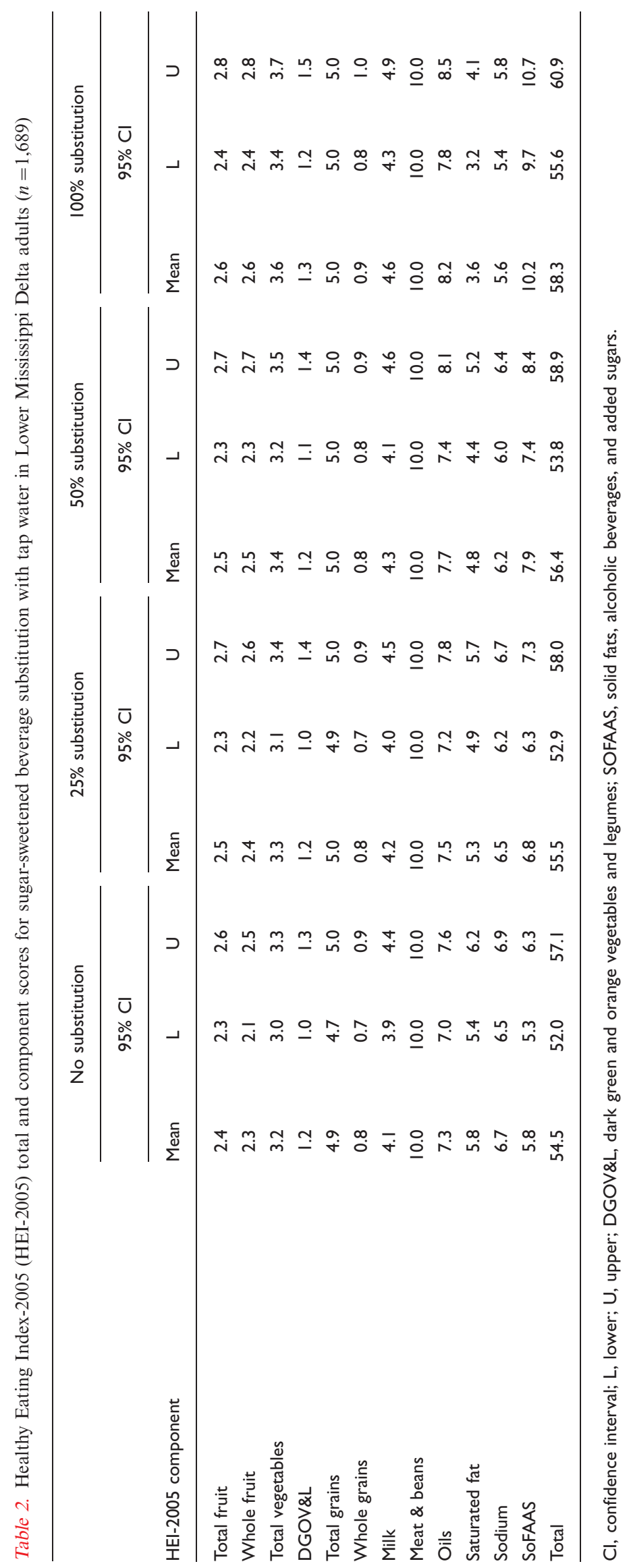


Table 3. Changes in Healthy Eating Index-2005 (HEI-2005) solid fats, alcoholic beverages, and added sugars (SoFAAS) component score, HEI-2005 total score, and total energy intake for substituting sugar-sweetened beverages (SSBs) with tap water in Lower Mississippi Delta adults $(n=1,689)$

\begin{tabular}{|c|c|c|c|c|}
\hline \multirow[b]{2}{*}{ Substitution level } & \multicolumn{2}{|c|}{ HEI-2005 score changes } & \multicolumn{2}{|c|}{ Total energy intake changes ${ }^{a}$} \\
\hline & SoFAAS & Total & kcal & $\%$ \\
\hline 0.25 & 1.0 & 1.0 & -54 & -2.7 \\
\hline 0.5 & 2.1 & 1.9 & -108 & -5.4 \\
\hline I & 4.4 & 3.8 & -215 & -10.7 \\
\hline
\end{tabular}

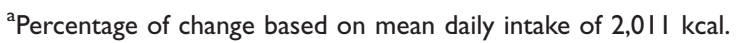

\section{Discussion}

To the best of our knowledge, this is the first study to report the simulated effects of replacing SSBs with tap water on diet quality and total energy intake. In this study, simulating the effects of substituting SSBs with tap water resulted in a theoretical 7\% increase in HEI-2005 total score. This represents a significant increase in diet quality; however, it is difficult to interpret this change in terms of reduced health risks because of the paucity of studies associating HEI-2005 scores with health and disease in adults. In low-income postpartum women, HEI-2005 total scores were negatively associated with body mass index, postpartum weight retention, lowdensity lipoprotein, and total cholesterol, and positively associated with high-density lipoprotein (18). The authors concluded that the strong relationship observed between HEI-2005 total scores with lipid profiles suggested that higher scores may translate to reduced risk for cardiovascular disease in low-income women, independent of body mass index. Hence, even a small increase in HEI-2005 total score, such as the 2.3-point increase for the $50 \%$ substitution in this study, may be sufficient to convey health benefits. In a second study, an inverse relationship was found between HEI-2005 total scores and colorectal cancer in both men and women, suggesting that adherence to federal dietary guidance is associated with reduced risk of colorectal cancer (19). Presumably, a $25 \%$ substitution of SSBs with water in the current study would be sufficient to move the LMD HEI-2005 population mean from the lowest to the second quintile reported by Reedy et al. (19), possibly imparting a protective effect against colorectal cancer. Although these two studies did find significant positive relationships between HEI-2005 total scores and specific health outcomes, caution should be used when translating these results to the current study's population due to the relatively small sample size of the first study and demographic and anthropometric differences among the study populations.

Although the increases in HEI-2005 total and solid fats, alcoholic beverages, and added sugars component scores found in this study are sufficient to warrant concentrated intervention efforts to replace consumption of SSBs with water or other non-caloric beverages in the LMD, perhaps the resulting projected reduction in energy consumed is even more compelling. Others have projected similar energy reductions resulting from decreased consumption of SSBs. Using a nationally representative sample of children and adolescents, Wang et al. estimated an average decrease in total energy intake of $235 \mathrm{kcal}$ per day with $100 \%$ replacement of SSBs with water (16). Stookey et al. predicted a mean decrease in total energy intake of 202 calories per day over time with $100 \%$ substitution of SSBs with water in a group of premenopausal overweight women (8).

Hypothetical body weight loss was not calculated and reported in this study due to the complex nature of weight loss that involves compensatory mechanisms influencing the control of energy balance. However, other investigators have reported modest weight loss associated with actual reductions in consumption of SSBs. In a randomized trial with prehypertensive adults, a reduction of one serving (12 fluid ounces) of SSBs per day was associated with a $0.7 \mathrm{~kg}$ weight loss at 18 months (20). Existing evidence, although limited, does suggest that encouraging water consumption and substituting water and other energy-free beverages for energy-containing beverages may facilitate weight management (21). Clearly, longitudinal studies designed to determine the impact of substituting SSBs with energy-free beverages on body weight are needed.

The benefits of reducing SSBs extend beyond weight loss. Reduction of SSBs has been strongly and positively associated with reduced blood pressure in more than one cohort of adults $(2,22-24)$. This is an important association because high blood pressure is a risk factor for a multitude of conditions, including cardiovascular disease, and even a small reduction in blood pressure (i.e. that achieved with reduced consumption of SSBs) can result in substantial health benefits (2). Additionally, consumption of SSBs has been associated with a higher risk of metabolic syndrome, type 2 diabetes, and coronary heart disease in adults even after accounting for other risk factors, including diet and lifestyle $(3,25)$. 
A major strength of this analysis is the use of the FOODS dataset. To our knowledge, this is the only dataset containing dietary intake measures on a representative sample of LMD adult residents. Because the FOODS sampling plan was designed to be representative of the LMD region, our results are generalizable to the entire LMD adult population. Furthermore, the dietary data were collected using multiple pass dietary recall methodology. This study did have limitations. The data were collected in 2000 and may not completely represent the current dietary intake of LMD adults. The demographic profile of the region may also have changed since 2000 because the populations of most LMD counties have been declining. A single 24-hour dietary recall is not an accurate measure of usual individual intake due to large day-to-day variability in food intake. However, at the group or population level, the mean of a single day of intake is highly reproducible (26) and can therefore be representative of a population's usual intake. Additionally, self-reported dietary assessment methods, such as 24-hour recalls, are prone to intake underreporting (12). It is likely that underreporting occurred in FOODS. If underreporting had not occurred, improvements resulting from SSB substitution with water may have been even larger. Finally, although the Dietary Guidelines for Americans 2005 has been replaced by the 2010 guidelines, there is currently no metric established to score diet quality based on the 2010 guidelines. Despite these limitations, this analysis used a unique and innovative approach to determine the potential magnitude of reducing SSB consumption on diet quality and energy intake, as moderation in SSB consumption is a key recommendation of the 2010 Dietary Guidelines for Americans (27) and remains a target among policy makers $(28,29)$.

Given that the highest rates of SSB consumption have occurred among populations at highest risk for obesity (1) and have been associated with less healthy eating behaviors such as eating at fast food restaurants and skipping breakfast, (30) efforts to curb the consumption of $\mathrm{SSBs}$ are sorely needed. In this study, a theoretical $100 \%$ substitution of SSBs with water substantially improved the diet quality of the LMD adult population and could potentially lead to significant weight loss over time. However, implementing dietary interventions in regions designated as food deserts, such as the LMD, can be challenging. The low availability of supermarkets and healthy foods in the LMD region has been highlighted in previous research as possible determinants of diet quality $(31,32)$. Hence, culturally sensitive interventions designed to encourage the replacement of SSBs with energy-free beverages in the LMD and similar disadvantaged regions should be tailored to focus on energy-free beverages that are acceptable to the majority of the target population. Such interventions may be the most efficacious approach for conveying potentially substantial health benefits in disadvantaged regions of the United States, where cultural dynamics have an immense influence on food choices and health practices (33).

\section{Conflict of interest and funding}

This study was sponsored in part by the US Department of Agriculture, Agricultural Research Service Projects 625153000-004-00D, and 6401-53000-001-00D. We would like to acknowledge the members of the FOODS working group of the Delta Nutrition Intervention Research Initiative who participated in the conceptualization, design, and implementation of the study. The contents of this publication do not necessarily reflect the views or politics of the USDA, nor does mention of trade names, commercial products, or organizations imply endorsement by the US Government.

\section{References}

1. Bleich SN, Wang YC, Wang Y, Gortmaker SL. Increasing consumption of sugar-sweetened beverages among US adults: 1988-1994 to 1999-2004. Am J Clin Nutr 2009; 89: 372-81.

2. Chen L, Caballero B, Mitchell DC, Loria C, Lin PH, Champagne $\mathrm{CM}$, et al. Reducing consumption of sugarsweetened beverages is associated with reduced blood pressure: a prospective study among United States adults. Circulation 2010; 121: 2398-406.

3. Fung TT, Malik V, Rexrode KM, Manson JE, Willett WC, Hu FB. Sweetened beverage consumption and risk of coronary heart disease in women. Am J Clin Nutr 2009; 89: 1037-42.

4. Hu FB, Malik VS. Sugar-sweetened beverages and risk of obesity and type 2 diabetes: epidemiologic evidence. Physiol Behav 2010; 100: 47-54

5. Malik VS, Popkin BM, Bray GA, Despres JP, Hu FB. Sugarsweetened beverages, obesity, type 2 diabetes mellitus, and cardiovascular disease risk. Circulation 2010; 121: 1356-64.

6. National Center for Chronic Disease Prevention and Health Promotion. Chronic disease Indicators [Internet]. Atlanta, GA: Centers for Disease Control and Prevention; 2009 [cited 9 May 2011]. Available at: http://apps.nccd.cdc.gov/cdi/

7. McCabe-Sellers BJ, Bowman S, Stuff JE, Champagne CM, Simpson PM, Bogle ML. Assessment of the diet quality of US adults in the Lower Mississippi Delta. Am J Clin Nutr 2007; 86: 697-706.

8. Stookey JD, Constant F, Gardner CD. Popkin BM. Replacing sweetened caloric beverages with drinking water is associated with lower energy intake. Obesity (Silver Spring) 2007; 15: 3013-22.

9. Tucker KL, Maras J, Champagne C, Connell C, Goolsby S, Weber J, et al. A regional food-frequency questionnaire for the US Mississippi Delta. Public Health Nutr 2005; 8: 87-96.

10. Thomson JL, Onufrak SJ, Connell CL, Zoellner JM, TussingHumphreys LM, Bogle ML, et al. Food and beverage choices contributing to dietary guidelines adherence in the Lower Mississippi Delta. Public Health Nutr. In press. doi: 10.1017/ S1368980011001443.

11. Champagne CM, Bogle ML, McGee BB, Yadrick K, Allen HR, Kramer TR, et al. Dietary intake in the lower Mississippi delta region: results from the Foods of our Delta Study. J Am Diet Assoc 2004; 104: 199-207.

12. Willett W. Nutritional epidemiology. New York, NY: Oxford University Press; 1998. 
13. Guenther PM, Reedy J, Krebs-Smith SM. Development of the Healthy Eating Index-2005. J Am Diet Assoc 2008; 108: 1896-901.

14. Friday JE, Bowman SA. MyPyramid equivalents database for USDA survey food codes, 1994-2002 version 1.0. [Online]. Beltsville, MD: USDA, Agricultural Research Service, Beltsville Human Nutrition Research Center, Community Nutrition Research Group; 2006 [cited 5 October 2010]. Available from: http://www.barc.usda.gov/bhnrc/fsrg

15. USDA Food and Nutrition Database for Dietary Studies, 1.0 [Internet]. Beltsville, MD: Agricultural Research Service, Food Surveys Research Group; 2004 [cited 5 October 2010]. Available from: http://www.ars.usda.gov/Services/docs.htm?docid=12068

16. Wang YC, Ludwig DS, Sonneville K, Gortmaker SL. Impact of change in sweetened caloric beverage consumption on energy intake among children and adolescents. Arch Pediatr Adolesc Med 2009; 163: 336-43.

17. Freedman LS, Guenther PM, Krebs-Smith SM, Kott PS. A population's mean Healthy Eating Index-2005 scores are best estimated by the score of the population ratio when one 24hour recall is available. J Nutr 2008; 138: 1725-9.

18. Shah BS, Freeland-Graves JH, Cahill JM, Lu H, Graves GR. Diet quality as measured by the healthy eating index and the association with lipid profile in low-income women in early postpartum. J Am Diet Assoc 2010; 110: 274-9.

19. Reedy J, Mitrou PN, Krebs-Smith SM, Wirfalt E, Flood A, Kipnis V, et al. Index-based dietary patterns and risk of colorectal cancer: the NIH-AARP Diet and Health Study. Am J Epidemiol 2008; 168: 38-48.

20. Karanja NM, Obarzanek E, Lin PH, McCullough ML, Phillips $\mathrm{KM}$, Swain JF, et al. Descriptive characteristics of the dietary patterns used in the dietary approaches to stop hypertension trial. DASH Collaborative Research Group. J Am Diet Assoc 1999; 99: S19-27.

21. Vitolins MZ, Tooze JA, Golden SL, Arcury TA, Bell RA, Davis $\mathrm{C}$, et al. Older adults in the rural South are not meeting healthful eating guidelines. J Am Diet Assoc 2007; 107: 265-72.

22. Brown IJ, Stamler J, Van Horn L, Robertson CE, Chan Q, Dyer $\mathrm{AR}$, et al. Sugar-sweetened beverage, sugar intake of individuals, and their blood pressure: international study of macro/ micronutrients and blood pressure. Hypertension 2011; 57: 695-701.

23. Dhingra R, Sullivan L, Jacques PF, Wang TJ, Fox CS, Meigs JB, et al. Soft drink consumption and risk of developing cardiometabolic risk factors and the metabolic syndrome in middle-aged adults in the community. Circulation 2007; 116: 480-8.
24. Winkelmayer WC, Stampfer MJ, Willett WC, Curhan GC. Habitual caffeine intake and the risk of hypertension in women. JAMA 2005; 294: 2330-5.

25. Malik VS, Popkin BM, Bray GA, Despres JP, Willett WC, Hu FB. Sugar-sweetened beverages and risk of metabolic syndrome and type 2 diabetes: a meta-analysis. Diabetes Care 2010; 33: 2477-83.

26. Gersovitz M, Madden JP, Smiciklas-Wright H. Validity of the 24-hour dietary recall and seven-day record for group comparisons. J Am Diet Assoc 1978; 73: 48-55.

27. US Department of Agriculture and US Department of Health and Human Services. Dietary Guidelines for Americans 2010. Washington, DC: US Government Printing Office; 2010 Dec. 95 p.

28. Brownell KD, Frieden TR. Ounces of prevention - the public policy case for taxes on sugared beverages. N Engl J Med 2009; 360: 1805-8.

29. Powell LM, Chaloupka FJ. Food prices and obesity: evidence and policy implications for taxes and subsidies. Milbank Quarterly 2009; 87: 229-57.

30. Sharkey JR, Johnson CM, Dean WR. Less-healthy eating behaviors have a greater association with a high level of sugarsweetened beverage consumption among rural adults than among urban adults. Food \& Nutrition Research 2011; 55: 5819 - DOI: $10.3402 /$ fnr.v55i0.5819.

31. Blanchard $\mathrm{T}$ (Deparment of Sociology, Anthropology, and Social Work, Mississippi State University, Starkville, MS), Lyson T (Development Sociology, Cornell University, Ithaca, NY). Food availability and food deserts in the nonmetropolitan South. Final report Apr 2006. Mississippi State, MS: Southern Rural Development Center: 2006. 7 p. Report No.: 12.

32. Connell CL, Yadrick MK, Simpson P, Gossett J, McGee BB, Bogle ML. Food supply adequacy in the Lower Mississippi Delta. J Nutr Educ Behav 2007; 39: 77-83.

33. Zoellner J, Bounds W, Connell C, Yadrick K, Crook L. Meaningful messages: adults in the Lower Mississippi Delta provide cultural insight into strategies for promoting the MyPyramid. J Nutr Educ Behav 2010; 42: 41-50.

* Jessica L. Thomson

USDA ARS, 284 Knapp Hall

Human Nutrition and Food

LSU AgCenter

Baton Rouge, LA 70803, USA

Tel: + (225) 8923662

Fax: + (225)578 4443

Email: jessica.thomson@ars.usda.gov 